\title{
ULAM STABILITY OF AN ADDITIVE-QUADRATIC FUNCTIONAL EQUATION IN BANACH SPACES
}

\author{
INHO HWANG AND CHOONKIL PARK
}

Abstract. Using the fixed point method and the direct method, we prove the Hyers-Ulam stability of the following additive-quadratic functional equation

$$
f(x+y, z+w)+f(x-y, z-w)-2 f(x, z)-2 f(x, w)=0 .
$$

Mathematics subject classification (2010): 39B52, 47H10, $39 \mathrm{~B} 62$.

Keywords and phrases: Hyers-Ulam stability, fixed point method, additive-quadratic functional equation, direct method.

\section{REFERENCES}

[1] T. AOKI, On the stability of the linear transformation in Banach spaces, J. Math. Soc. Japan 2 (1950), 64-66.

[2] L. CĂDARIU, V. RADU, Fixed points and the stability of Jensen's functional equation, J. Inequal. Pure Appl. Math. 4, no. 1, Art. ID 4 (2003).

[3] L. CĂDARIU, V. RADU, On the stability of the Cauchy functional equation: a fixed point approach, Grazer Math. Ber. 346 (2004), 43-52.

[4] L. CĂDARIU, V. RADU, Fixed point methods for the generalized stability of functional equations in a single variable, Fixed Point Theory Appl. 2008, Art. ID 749392 (2008).

[5] J. DiAz, B. MARGolis, A fixed point theorem of the alternative for contractions on a generalized complete metric space, Bull. Am. Math. Soc. 74 (1968), 305-309.

[6] Y. Ding, T.-Z.XU, Approximate solution of generalized inhomogeneous radical quadratic functional equations in 2-Banach spaces, J. Inequal. Appl. 2019, 2019:31, 13 pp.

[7] A. Ebadian, S. Zolfagfhari, S. Ostadbashi, C. Park, Approximation on the reciprocal functional equation in several variables in matrix non-Archimedean random normed spaces, Adv. Difference Equ. 2015, 2015:314, 13 pp.

[8] I. EL-FASSI, Generalized hyperstability of a Drygas functional equation on a restricted domain using Brzdek's fixed point theorem, J. Fixed Point Theory Appl. 19 (2017), 2529-2540.

[9] I. EL-FASSI, Solution and approximation of radical quintic functional equation related to quintic mapping in quasi- $\beta$-Banach spaces, Rev. R. Acad. Cienc. Exactas Fís. Nat. Ser. A Mat. 113 (2019), no. 2, 675-687.

[10] M. Eshaghi Gordu, N. Ghobadipour, Stability of $(\alpha, \beta, \gamma)$-derivations on Lie $C^{*}$-algebras, Int. J. Geom. Meth. Mod. Phys. 7 (2010), 1097-1102.

[11] W. FECHNER, Stability of a functional inequalities associated with the Jordan-von Neumann functional equation, Aequationes Math. 71 (2006), 149-161.

[12] P. GǍvRUTA, A generalization of the Hyers-Ulam-Rassias stability of approximately additive mappings, J. Math. Anal. Appl. 184 (1994), 431-436.

[13] A. Gilányi, Eine zur Parallelogrammgleichung äquivalente Ungleichung, Aequationes Math. 62 (2001), 303-309.

[14] A. GilÁnYi, On a problem by K. Nikodem, Math. Inequal. Appl. 5 (2002), 707-710.

[15] D.H. Hyers, On the stability of the linear functional equation, Proc. Nat. Acad. Sci. U.S.A. 27 (1941), 222-224. 
[16] G. IsAC, TH. M. Rassias, Stability of $\psi$-additive mappings: Applications to nonlinear analysis, Int. J. Math. Math. Sci. 19 (1996), 219-228.

[17] D. Mineţ, V. RADU, On the stability of the additive Cauchy functional equation in random normed spaces, J. Math. Anal. Appl. 343 (2008), 567-572.

[18] C. PARK, Additive $\rho$-functional inequalities and equations, J. Math. Inequal. 9 (2015), 17-26.

[19] C. PARK, Additive $\rho$-functional inequalities in non-Archimedean normed spaces, J. Math. Inequal. 9 (2015), 397-407.

[20] C. PARK, Fixed point method for set-valued functional equations, J. Fixed Point Theory Appl. 19 (2017), 2297-2308.

[21] V. RADU, The fixed point alternative and the stability of functional equations, Fixed Point Theory 4 (2003), 91-96.

[22] TH. M. Rassias, On the stability of the linear mapping in Banach spaces, Proc. Am. Math. Soc. 72 (1978), 297-300.

[23] J. RÄTZ, On inequalities associated with the Jordan-von Neumann functional equation, Aequationes Math. 66 (2003), 191-200.

[24] L. SZÉKELYHIDI, Superstability of functional equations related to spherical functions, Open Math. 15 (2017), no. 1, 427-432.

[25] S. M. Ulam, A Collection of the Mathematical Problems, Interscience Publ. New York, 1960. 